\title{
Human body skin surface distribution as measured by infrared thermography in altitude hypoxia conditions.
}

\author{
by J.Laszczynska ${ }^{1}$, R. Kaczanowski ${ }^{1}$, K. Wójcik ${ }^{1}$, P. Sacha ${ }^{2}$, \\ J. Lukasiewicz ${ }^{2}$ and W. Kowalski ${ }^{1}$
} 'Polish Air Force Institute of Aviation Medicine, Aerospace Physiology Laboratory, 01-755 Warsaw,
Poland; '2 Polish Air Force Institute of Technology, Thermovision Laboratory, Warsaw, Poland

\begin{abstract}
A group of seven males was tested inside a thermobarochamber. Every subject was examined in the same manner in a simulated altitude of: $2500,3500,4500 \mathrm{~m}$ 0.s.l. (control at $115 \mathrm{~m} \mathrm{0.s.l.)} \mathrm{After} 20$ minutes of adaptation the 25 minutes exposition to altitude hypoxia was performed. Thermovisual measurement (AGEMA Thermovision 900 series) was repeated at $5 \mathrm{~min}$. intervals. The results demonstrated that the range and dynamics of temperature distribution were proportional to the intensity of altitude hypoxia and the exposure time. Observed changes depend on the area of body surface.
\end{abstract}

\section{Introduction}

The pilot in his work environment is exposed to several physical stimuli. High altitude hypoxia is one of the major threats to his well being and his ability to perform high demand tasks. In hypoxia conditions limited oxygen supply to the tissue decreases general energetic potential of human organism. This is expressed in the numerous number of published research in the field of hypothermic effect of altitude hypoxia.

As skin temperature is assumed to reflect the state of local peripheral circulation (blood flow), an effort was made to study the effect of simulated altitude on the pattern of skin body temperatures and radiance, aimed at the determination of these body surface areas which are the most susceptible to this stimulus.

\section{Methods}

The study was performed in the group of seven male subjects, who gave a written consensus to participate as paid volunteers in the study. Their mean ( $+S E$ ) age was of $28+2$ years, height and weight of $171 \pm 1 \mathrm{~cm}$ and $78 \pm 7 \mathrm{~kg}$, respectively. The screening procedure for subjects was performed at the licensing division of Institute. Their physical fitness was evaluated by $\mathrm{VO}_{2} \max$.

The experiment was carried out in the thermobarochamber in controlled environmental conditions (ambient temperature $=24.0 \%$, relative humidity $=45 \%$, air flow rate below 0.2 $\mathrm{m} / \mathrm{s}$ ). The inhomogenity of air temperature in the test chamber did not exceed $0.1^{\circ} \mathrm{C} / \mathrm{m}$. Each of the subjects was exposed to the same stimulus as regards to the time and rate of altitude change, reaching the hypoxia levels corresponding to the altitude of 2500,3500 and $4500 \mathrm{~m}$ over sea level (o.s.I.) which were assumed to be the threshold levels for physiological reaction under study. The control data were gathered in the same group of subjects, at the pressure corresponding to the altitude of $115 \mathrm{~m}$ o.s.I. Each test run consisted of the 20 minutes of adaptation period (base line) and the 25 minutes of exposure to the pre-set level of altitude hypoxia. Also simultaneously the continuous acquisition of physiological parameters (heart rate, deep body temperature and blood oxygen saturation) was performed. The 4 day minimal intervals between consecutive test runs were kept as a rule.

The evaluation of body surface temperatures was performed with AGEMA Thermovision 900 Series, scanner LW, lens with view angle of $20^{\circ}$. The measurement was performed inside the thermobarochamber and repeated at $5 \mathrm{~min}$. intervals, using three body positions, from a distance of 3 meters. Transmission was estimated using the LOWTRAN model. The Erica 3.11 software was used together with the RAD 1.2 option for software implementation of the radiance model. The distribution of radiance in the 20 selected body areas and their maximal values were computed in 1000 measurement points. 


\section{Results}

It was found that as the hypoxia is getting higher, not only a mean surface temperature but also a deep body temperature decrease, which is known as the "hypothermic effect" of hypoxia. The most pronounced changes were observed at an altitude of $4500 \mathrm{~m}$ over sea level (figure 1.). As referred to the control values the apparent decrease of temperature in the area of the thorax and distal part of the body (upper and lower limbs) were observed. Under these conditions the relative share of the lower isotherms areas increased by $30 \%$. In the condition of steady state of hypoxia level the heat loss (by radiation) from the body decreased. Changes of body radiance were proportional to the intensity of hypoxia level. The radiance values were specific for different body surface areas e.g.: chest, thigh, arm, and forearm. The strongest differences were observed in the chest area (figure 2.). Between skin body area of upper and lower limbs the small quantity differences were recorded. The radiance heat flow from the body extremities reached the lowest values $10 \mathrm{~min}$. after the application of the stimulus. During 25 minutes of exposure the radiance of the chest surface gradually decreased and the lowest values were recorded at the last minute of exposure (figure 3.). There was no correlation between the range and the time dynamics of the temperature patterns of skin temperatures and arterial blood oxygen saturation.

\section{Conclusion}

Under altitude hypoxia conditions the general metabolic level decreased as a result of the limitation of oxygen content in the atmosphere. These changes result in the restriction of the body heat content. Thermoregulatory reactions of the body reduced the heat flow from the inside ("core") to the peripheral layer ( ${ }_{n}$ shell") of the body. Under such conditions the vasoconstriction of skin blood vessels allows to preserve the necessary amount of heat inside the body according to the rule of the state of body heat balance. Thermography in particular has made it possible to record in real time the temperature distribution of large areas of the body surface. Modern image processing methods permit to perform the dynamic studies. Such detailed knowledge as thermographic analysis demonstrating temperature distribution changes on the whole body surface allowed to define such skin areas which are extremely susceptible to the stimulus of altitude hypoxia. The biggest changes were recorded at $4500 \mathrm{~m}$ o.s.l. In spite of apparent decrease of radiant heat emission from body surface during $25 \mathrm{~min}$. of exposure to altitude hypoxia conditions the differentiation of radiance values between chest and upper or lower limbs were observed.

The information about temperature distribution and thermal emission from body surface is very important for practical applications. The results complete the early studies concerning body heat elimination in pilot's wearing pressurised suits [1-2.]. Air crew are usually covered in mulfi-layer protective clothing. The effects of clothing on human heat exchange are extremely complicated and difficult to describe in exact mathematical terms. The results allowed to consolidate the relative share of the lowest temperature areas of body surface and its variations under steady state hypoxia conditions. It is very important for human body protection from positive or negative stimulus of thermal surroundings. Thermovision image creates the opportunity to define human body thermal balance more accurately. The definition of radiance in selected body areas is very helpful when establishing the hygienic properties of the examined air crew clothing. It also allows for conclusions concerning thermal body protection in extreme conditions, such as exposure to high altitude hypoxia.

\section{Acknowledgements}

This research was financed by State Scientific Committee and PAF IAM.

\section{REFERENCES}

[1] LASZCZYNSKA J. - Heat elimination in subjects using a pressurised suit during exposure to high ambient temperatures, Ergonomia, 1990, 13, 1, pp. 7-18

[2], LASZCZYNSKA J., WOJCIK K., SACHA P. AND OKINCZYC A. - The appraisal of radiation energy emitted by the surface of WUK-90 suit user in different thermal conditions, Polski Przeglad Medycyny Lotniczej, 1995, 2, 1, pp.145-156 


\section{http://dx.doi.org/10.21611/qirt.1996.055}

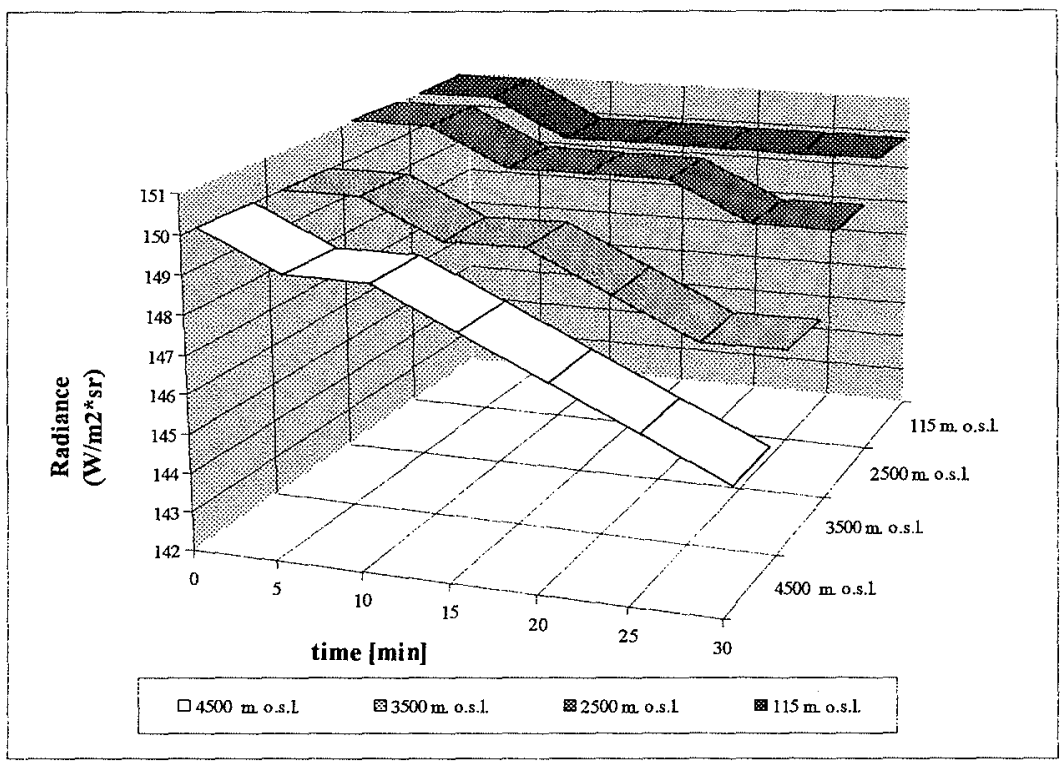

Fig.2. Radiance of chest skin surface at:115 (control), 2500,3500 and $4500 \mathrm{~m}$. over sea level $[0.000-$ INF $(\mu \mathrm{m})]$.

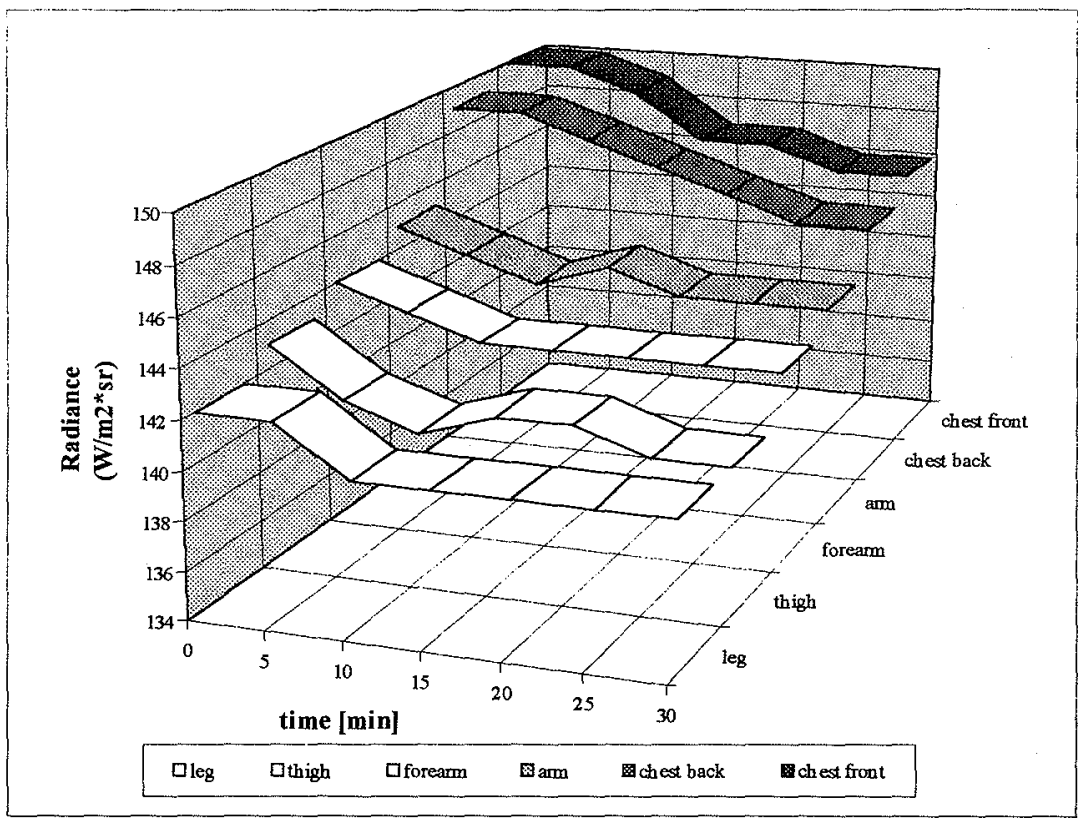

Fig. 3. Radiance of human body surface at $4500 \mathrm{~m}$. over sea level $[0.000-\operatorname{INF}(\mu \mathrm{m})]$, 

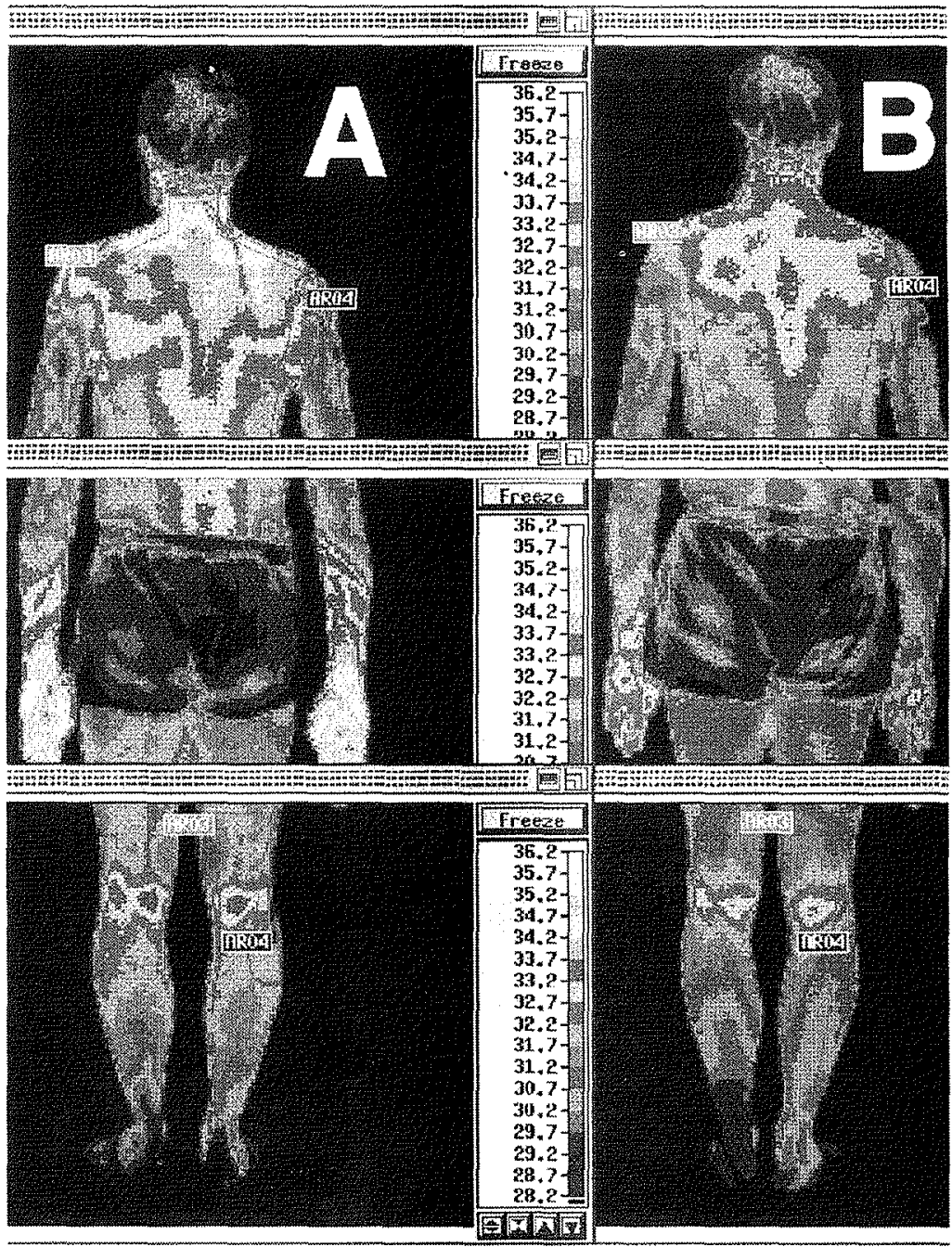

Fig. 1. Thermographic image of human body surface in control (A) and after $30 \mathrm{~min}$. exposure to high altitude hypoxia (4500 $\mathrm{m}$ 0.s.l.) (B) 